\title{
Qualidade das águas em áreas urbanas do rio Taquari nos municípios de Estrela e Lajeado - RS
}

\author{
Quality of the waters in urbane areas of the Taquari river in the local authorities of \\ Estrela and Lajeado - RS
}

\author{
Nilma Silvania Izarias ${ }^{* 1}$, Ademir Cássio Machado Peranzoni² ${ }^{2}$ Giovana Aparecida \\ Kafer $^{3}$, Aldeni Mello de Oliveira ${ }^{2}$, Aldileia da Silva Souza ${ }^{4}$, Eniz Conceição Oliveira ${ }^{5}$, \\ Eduardo Rodrigo de Santana ${ }^{6}$
}

\author{
${ }^{1}$ Mestre em Meio Ambiente, Docente de química geral e ambiental, Coordenadora da área de química, \\ Instituto Federal de Goiás, Uruaçu, Brasil. \\ ${ }^{2}$ Mestrando em Ciências Exatas, Licenciado em Ciências Biológicas, UNIVATES, Lajeado, Brasil. \\ ${ }^{3}$ Mestranda em Ciências Exatas, Licenciada em Ciências Naturais e Matemática, UNIVATES, Lajeado, Brasil. \\ ${ }^{4}$ Mestranda em Ciências Exatas, Licenciada em Pedagogia, UNIVATES, Lajeado, Brasil. \\ ${ }^{5}$ Doutora em Química (UFRGS), Coordenadora e Docente da Pós graduação stricto sensu (Mestrado e Dourado) em ambiente e \\ desenvolvimento, UNIVATES, Lajeado, Brasil. \\ ${ }^{6}$ Doutor em Engenharia de Minas, Metalúrgica e de Materiais (UFRGS), Docente da Pós graduação stricto sensu (Mestrado e \\ Dourado) em ambiente e desenvolvimento, UNIVATES, Lajeado, Brasil
}

\begin{abstract}
Resumo
A água é parte integrante do meio ambiente, no entanto, a forma como está sendo empregada não condiz com o essencial e necessário para o alcance da sustentabilidade. Desta forma, estabeleceu-se uma investigação buscando verificar a qualidade da água do rio Taquari, vazante entre os municípios de Lajeado e Estrela no Rio Grande do Sul, com o objetivo de contribuir, com os dados levantados pelo comitê de bacia da região, poder público e pela coletividade. Coletou-se amostras simples de água do rio Taquari para as análises físicas de: temperatura, turbidez, cor, sólidos dissolvidos totais. E, químicas de: $\mathrm{pH}$, condutividade, dureza, fluoreto, cloreto, fósforo total, N-nitrito, N-nitrato, nitrogênio - total, sulfato, C-orgânico, C-inorgânico, e C-total, oxigênio dissolvido bem como da presença de microrganismos patogênicos. As análises foram realizadas nos laboratórios do Centro Universitário Univates de Lajeado. Como resultado as águas do rio Taquari são de boa qualidade, estando em conformidade com os padrões estabelecidos pela resolução CONAMA 357/2005, exceto para o parâmetro fósforo e microrganismo Ascaris lumbricoides, que podem ser um indicativo de poluição por esgoto doméstico. Espera-se que estes dados investigados possam contribuir para tomada de ações que visem prevenir, remediar ou extinguir os possíveis agentes poluidores do rio Taquari. Palavras-chave: Rio Taquari, Qualidade da água, Monitoramento ambiental.
\end{abstract}

\begin{abstract}
The water is an integrant part of the environment, however, the form as it is being employed does not match the essential and necessary thing for the reach of the sustentabilidade. In this way, an investigation was established looking to check the quality of the water of the river Taquari, ebb tide between the local authorities of Paved and It shines in Rio Grande do Sul, with the objective to contribute, with the data lifted by the committee of basin of the region, public power and for the community. There were collected simple samples of water of the river Taquari for the physical analyses of: temperature, turbidez, color, dissolved total solids. And, chemists of: $p H$, condutividade, hardness, fluoreto, chloride, total match, N-nitrito, N-nitrate, nitrogen - total, sulphate, C-organic, C-inorganic, and C-total, dissolved oxygen as well as of the presence of microorganisms patogenicos. The analyses were carried out in the laboratories of the University Centre Univates When of It Was Paved. Since when it resulted the waters of the river Taquari are of good quality, when there are in accordance with the standards established by the resolution CONAMA 357/2005, except for the parameter match and microorganism Ascaris lumbricoides, which can be an indicative of pollution for domestic drain. It is waited that these investigated data could contribute to capture of actions that aim to prevent, to put right or to extinguish the possible pollutant agents of the river Taquari Keywords: Taquari river, Quality of the water, Environmental Monitoramento.
\end{abstract}

*nilmaizarias@hotmail.com

Recebido: 08/04/2014 Aceito: 08/04/2014 


\section{Introdução}

$\mathrm{O}$ Brasil detém 11,6\% da água doce superficial do mundo. Entretanto $70 \%$ dessa água está localizada na Região Amazônica, restando apenas $30 \%$ distribuída desigualmente pelo País, para atender a $93 \%$ da população (MEZOMO, 2009). O Estado do Rio Grande do Sul concentra aproximadamente 6,13\% da população brasileira, e a bacia hidrográfica Taquari-Antas é a segunda maior do Estado, situando-se na região nordeste e abrangendo uma área de $26.428 \mathrm{~km}^{2}$, equivalente a $9 \%$ do território estadual, e 98 municípios integrantes desta bacia concentram $20 \%$ do PIB estadual (FEPAM, 2014).

Os municípios pertencentes à bacia Taquari-Antas apresentam um elevado grau de urbanização, e exploram as águas da bacia, principalmente com as atividades de abastecimento público e industrial, irrigação, piscicultura, dessedentação animal, geração de energia, diluição de esgoto doméstico, pesca, lazer e drenagem urbana. As cidades de Estrela e Lajeado-RS pertencem a essa bacia e são banhadas pelas águas do Rio Taquari. (FEPAM, 2014; FERRI, 2012).

A "Declaração Universal dos Direitos da Água" trouxe em seu $1^{\circ}$ artigo as discussões de que "a água faz parte do patrimônio do planeta" e de que "cada cidadão é plenamente responsável aos olhos de todos" (ONU, 1992). Nessa perspectiva, o monitoramento e o controle visam a qualidade das águas superficiais em regiões urbanas.

A qualidade da água depende do uso para o qual ela se destina (TOLEDO e NICOLELLA, 2002). Segundo Ferri (2012), no Plano da bacia Taquari-Antas, os relatórios das etapas A e B descrevem o alto índice de poluição, o que possibilitou a classificação de suas águas como classe 04, de acordo com a resolução 357 do Conselho Nacional do Meio Ambiente (BRASIL, 2005). Para a FEPAM (2014), diante de um monitoramento trienal das águas desde 1993, utilizando o índice de qualidade da água (IQA) apresentado pelo NSF-National Sanitation Foundation, as águas da bacia são classificadas como regulares a boa dependendo do trecho analisado.

As Resoluções nº 357 e nํㅜ 420 do Conselho Nacional do Meio Ambiente (BRASIL, 2005; 2009) estabelecem padrões para a classificação das águas, em função das concentrações das espécies químicas presentes e dependendo do ambiente e da classe do corpo d'água. Entre os parâmetros usados para avaliar a qualidade das águas ressaltam-se os físico-químicos e microbiológicos, viabilizando um diagnóstico sob o ponto de vista qualitativo e quantitativo quanto à presença $\mathrm{e}$ concentração de diferentes espécies químicas.

Desta forma, estudos têm procurado avaliar a concentração de espécies químicas e biológicas da água para indicar a qualidade dos corpos hídricos (PINHEIRO \& DESCHAMPS, 2008). Teodoro et al., (2007) discutem que as alterações ocorridas em uma bacia hidrográfica podem ser avaliadas por meio de suas características físicas, bem como através do monitoramento de parâmetros de qualidade de águas superficiais. Pinheiro, et al., (2013, p. 87) citando Caovilla et al., (2005) e Piovesan et al., (2009) dizem que, para uma melhor gestão da água fazse necessário avaliar "a distribuição espacial de fontes de poluição difusa" e os "impactos dos diferentes usos do solo" ou ainda, "estimar o aporte de nutrientes".

Assim, o objetivo deste trabalho é verificar a qualidade das águas do rio Taquari em áreas urbanas nas cidades de Estrela e Lajeado - RS, por meio de análises físico-químicas e microbiológicas e comparar as concentrações encontradas com as Resoluções CONAMA no $357 / 2005$, contribuindo com o levantamento de dados do comitê de bacia da região, com o poder público e com a coletividade.

\section{Materiais e métodos}

Para o desenvolvimento deste trabalho foram coletadas amostras de água do Rio Taquari, em áreas urbanizadas dos municípios de Lajeado e Estrela - RS. Este rio faz parte da bacia hidrográfica do sistema Taquari-Antas e situa-se na região nordeste do Estado do Rio Grande do Sul (FEPAM, 2014).

Os pontos de coleta da água foram denominados de RT1, RT2, RT3, RT4 e RT5, e apresentam as seguintes coordenadas geográficas: RT1: $29^{\circ} 30^{\prime} 14^{\prime \prime}$ 'S e $51^{\circ} 58^{\prime} 19^{\prime \prime} \mathrm{W}$; RT2: $29^{\circ} 29^{\prime} 55^{\prime} \mathrm{S}$ e $51^{\circ} 58^{\prime} 01^{\prime \prime} \mathrm{W}$; RT3: $29^{\circ} 29^{\prime} 25^{\prime \prime} \mathrm{S}$ e 51 ${ }^{\circ} 58^{`} 31^{\prime \prime} \mathrm{W}$; RT4: $29^{\circ} 28^{\prime} 13^{\prime \prime} \mathrm{S}$ e $51^{\circ} 57^{\prime} 33^{\prime \prime} \mathrm{W}$; RT5: $29^{\circ} 28^{\prime} 11^{\prime \prime} \mathrm{S}$ e $51^{\circ} 57^{\prime} 27^{\prime \prime} \mathrm{W}$.

As amostras de água foram coletadas a cerca de 30 $\mathrm{cm}$ de profundidade, utilizando um coletor de água de metal inoxidável, sendo $1000 \mathrm{~mL}$ da água transferida para frascos de polietileno de alta densidade, devidamente identificado e transportado até o laboratório. In loco, mediu-se a temperatura da água com termômetro de vidro de coluna de mercúrio de escala externa $10^{\circ} \mathrm{C}$ a $+110^{\circ} \mathrm{C}$, marca Incoterm; oxigênio dissolvido (O.D), com oxímetro digital, marca HANNA, modelo HI9146N-04. As demais análises físicas, químicas e microbiológicas foram realizadas nos laboratórios do Centro Universitário Univates.

Para as análises de turbidez, $\mathrm{pH}$, condutividade e sólidos totais secos utilizaram-se os respectivos equipamentos: turbidímetro Digimed HANNA modelo HI 93703C, medidor de $\mathrm{pH}$ digital Digimed, modelo DM-20; condutivímetro OKTON CON5 Acron Series; manta de aquecimento Velp Scientifica RC2, manta de aquecimento Velp Scientifica ARE, estufa Quimis Q-317B-32, balança analítica - Marca Bel Engineering Modelo Mark 210A e, o equipamento TO-VCPH, marca Shimadzu de acordo com as normas (ALPHA, 1998).

O fósforo foi analisado utilizando-se o POPFQ UNI406, Rev. 7, usando método 4500-B.5 e 4500-E. A dureza foi analisada por método titulométrico, ambas 
de acordo com as normas (ALPHA, 1998). Os ensaios foram realizados em temperatura ambiente.

Os íons: fluoretos $\left(\mathrm{F}^{-}\right)$, cloretos $\left(\mathrm{Cl}^{-}\right)$, nitratos $\left(\mathrm{NO}_{3}^{-}\right)$, nitritos $\left(\mathrm{NO}_{2}^{-}\right)$e sulfatos $\left(\mathrm{SO}_{4}^{2-}\right)$, foram analisados utilizando-se cromatógrafo iônico - IC, com detector de condutividade 1, modelo 881 Compact IC pro 1, com tempo de condutividade $18 \mathrm{~min}$, utilizando volume de injeção da amostra de $20 \mu \mathrm{L}$ em coluna analítica Metrosep A Supp 5 - 150/4.0, com eluentes de ânions $0,339 \mathrm{~g} / \mathrm{L}$ de $\mathrm{Na}_{2} \mathrm{CO}_{3}, 0,840 \mathrm{~g} / \mathrm{L}$ de $\mathrm{NaHCO} 3$ de água ultra pura, fluxo $0,700 \mathrm{~mL} / \mathrm{min}$, pressão de $9,30 \mathrm{MPa}$, temperatura $300 \mathrm{C}$.

As análises microbiológicas foram realizadas utilizando-se microscópio óptico eletrônico de marca Olympus. A respectiva análise foi feita por microscopia direta.

\section{Resultados e discussões}

De acordo com Von Sperling (2005), a qualidade de uma determinada água depende das condições naturais e da atuação do homem na bacia hidrográfica, sua exploração e gestão dependem da capacidade suporte do corpo d'água, dos padrões de qualidade, da emissão de poluentes, da disponibilidade tecnológica e dos aspectos sociais.

No Brasil, a Resolução CONAMA 357, de 17 de março de 2005 “dispõe sobre a classificação dos corpos de água e diretrizes ambientais para o seu enquadramento, bem como estabelece as condições e padrões de lançamento de efluentes" (BRASIL, 2005, p.01). Esta resolução determina valores máximos e mínimos para diversas variáveis em sistemas de água doce e, foi alterada em 13 de maio de 2011, pela resolução CONAMA no ${ }^{\circ}$ 430. Estes documentos, tornaram se referência para pesquisas e "frequentemente geram comparações entre os resultados obtidos em determinado ambiente aquático e os respectivos limites associados aso seu enquadramento" (CUNHA et al., 2013 p. 160).

\subsection{Resultados das análises Físico-Químicas}

Todos os resultados numéricos obtidos no presente trabalho estão apresentados na tabela 01 . Cada coluna evidencia as concentrações ou valores encontrados na resolução CONAMA 357/2005, os valores medidos em cada ponto de amostragem (de RT1 a RT5) e as médias aritméticas dos pontos coletados estão dispostos na tabela 1.

Analisando os resultados apresentados na Tabela 1 , as amostras coletadas no Rio Taquari indicaram aspectos de soluções levemente alcalinas, devido aos valores encontrados no $\mathrm{pH}$, acima de 7,0. Apresentam baixa turbidez e a cor um pouco acima do padrão determinado pela resolução CONAMA 357/2005. Para os sólidos dissolvidos, a resolução CONAMA 357/2005 estabelece um limite máximo de $500 \mathrm{mg} / \mathrm{L}$ para as águas de classe I e II. A média dos valores encontrados nas análises foi de $0,20 \mathrm{mg} / \mathrm{L}$. Um valor relativamente baixo quando comparado ao padrão estabelecido. Segundo Von Sperling (2005), nas águas naturais os sólidos estão constituídos, principalmente, de carbonos, bicarbonatos, sulfatos e fosfatos, podendo ocorrer também nitratos de cálcio e de magnésio. "Os sólidos podem causar danos aos peixes e à vida aquática. Eles podem sedimentar no leito dos rios destruindo organismos que fornecem alimentos ou também, danificar os leitos de desova de peixes" (CETESB, 2009 p. 03).

A temperatura e a concentração total de substâncias ionizadas dissolvidas interferem na condutividade elétrica da água. As altas concentrações dos íons $\mathrm{H}^{+}$ e $\mathrm{OH}^{-}$são diretamente responsáveis pelos valores da condutividade, mas outros íons como os de: cálcio, magnésio, potássio, sódio, carbonatos, carbonetos, sulfatos e cloretos, também interferem na condutividade. O parâmetro condutividade elétrica pode contribuir para possíveis reconhecimentos de impactos ambientais que ocorram na bacia de drenagem ocasionados por lançamentos de resíduos industriais, mineração, esgotos, etc. (LIMA e GARCIA, 2008; SILVA et al., 2010).

A média dos resultados encontrados para a condutividade nas amostras analisadas foi de 46,93 $\mathrm{\mu S} /$ $\mathrm{cm}$. De acordo com CETESB (2009), as águas naturais apresentam teores de condutividade na faixa de 10 a $100 \mu \mathrm{S} / \mathrm{cm}$. Em geral, níveis superiores a $100 \mu \mathrm{S} / \mathrm{cm}$ indicam ambientes impactados. Em ambientes poluídos por esgotos domésticos ou industriais os valores podem chegar até $1.000 \mu \mathrm{S} / \mathrm{cm}$. A água pura pode ser classificada em função da condutividade, sendo que para a água mineral a condutividade determinada varia de 30 a $700 \mu \mathrm{S} / \mathrm{cm}$ e a água considerada potável um valor menor que $700 \mu \mathrm{S} / \mathrm{cm}$. A Organização Mundial da Saúde (OMS) e a portaria 518/2004 do ministério da saúde não fazem referências a limites de condutividade elétrica na água (BRASIL, 2004). No entanto segundo Kedimerich et al., (2012) a condutividade elétrica em águas doces varia de $10 \mathrm{a} 1000 \mu \mathrm{S} / \mathrm{cm}$.

O parâmetro dureza carbonatada não evidencia problemas sanitários, e alguns estudos realizados em áreas de maior dureza, indicaram uma menor incidência de problemas cardíacos. Von Sperling (2005) discute que em determinadas concentrações causam sabor desagradável e podem ter efeitos laxativos; reduz a formação de espumas, indicando um maior consumo de sabão; causa incrustações nas tubulações de água quente, caldeiras e aquecedores.

As águas do rio Taquari apresentam dureza com um valor médio de $26,53 \mathrm{mg} \mathrm{CaCO} / \mathrm{L}$, suas águas podem ser consideradas como água mole. De acordo com Von Sperling (2005) águas moles apresentam dureza menor que $50 \mathrm{mg} \mathrm{CaCO} / \mathrm{L}$.

As análises realizadas para os íons de Fluoreto $\left(\mathrm{F}^{-}\right)$ e Cloreto $\left(\mathrm{Cl}^{-}\right)$, apresentaram valores médios de 0,05 
Tabela 1 - Resultados das análises de água do rio Taquari nas cidades de Estrela e Lajeado -RS comparados com a resolução CONAMA 357/2005.

\begin{tabular}{|c|c|c|c|c|c|c|c|c|}
\hline \multirow[b]{2}{*}{ Parâmetro } & \multicolumn{2}{|c|}{$\begin{array}{c}\text { Resolução CONAMA } \\
357 / 2005 \\
\end{array}$} & \multicolumn{5}{|c|}{ AMOSTRAS } & \multirow[b]{2}{*}{ Média } \\
\hline & $\begin{array}{l}\text { Padrão } \\
\text { Classe } 1\end{array}$ & $\begin{array}{l}\text { Padrão } \\
\text { Classe } 2\end{array}$ & RT-1 & RT-2 & RT-3 & RT-4 & RT-5 & \\
\hline $\begin{array}{l}\text { *Temperatura } \\
\left({ }^{*} \mathrm{C}\right)\end{array}$ & $*$ & $*$ & 27,3 & 25,8 & 26,6 & 26,8 & 27,8 & 26,86 \\
\hline *Turbidez (NTU) & 40 & 100 & 23,0 & 23,3 & 22,7 & 22,1 & 21,2 & 22,46 \\
\hline${ }^{*}$ Cor $(\mathrm{PT}-\mathrm{Co})$ & $\mathrm{Pt} / \mathrm{L}$ & 75 & 77,5 & 76,5 & 79,3 & 73,1 & 74,7 & 76,22 \\
\hline $\begin{array}{l}\text { Sólidos dissolvidos } \\
\text { totais }(\mathrm{mg} / \mathrm{L})\end{array}$ & 500 & 500 & 0,192 & 0,197 & 0,237 & 0,195 & 0,190 & 0,202 \\
\hline $\mathrm{pH}$ & 6,0 a 9,0 & 6,0 a 9,0 & 7,76 & 7,55 & 7,52 & 7,42 & 7,36 & 7,52 \\
\hline $\begin{array}{l}\text { Condutividade } \\
(\mu \mathrm{S} / \mathrm{cm})\end{array}$ & * & * & 46,89 & 45,78 & 44,28 & 48,47 & 49,22 & 46,93 \\
\hline $\begin{array}{l}\text { Dureza } \quad(m g \\
\left.\mathrm{CaCO}_{3} / \mathrm{L}\right)\end{array}$ & $*$ & * & 15,49 & 31,65 & 24,24 & 32,32 & 28,95 & 26,53 \\
\hline $\begin{array}{l}\text { Fluoreto (F-) } \\
(\mathrm{mg} / \mathrm{L})\end{array}$ & 1,4 & 1,4 & 0,04 & 0,04 & 0,04 & 0,05 & 0,05 & 0,05 \\
\hline $\begin{array}{l}\text { Cloreto }\left(\mathrm{Cl}^{-}\right) \\
(\mathrm{mg} / \mathrm{L})\end{array}$ & 250 & 250 & 1,95 & 1,96 & 1,80 & 2,13 & 2,12 & 1,99 \\
\hline $\begin{array}{l}\text { Fósforo total } \\
(\mathrm{mg} / \mathrm{L})\end{array}$ & 0,025 & 0,075 & 0,147 & 0,144 & 0,158 & 0,155 & 0,169 & 0,150 \\
\hline $\begin{array}{l}\text { N-Nitrito }-\mathrm{NO}_{2}- \\
(\mathrm{mg} / \mathrm{L})\end{array}$ & 1,0 & 1,0 & 0,03 & 0,03 & 0,03 & 0,03 & 0,03 & $\mathrm{O}, 03$ \\
\hline $\begin{array}{l}\text { N-Nitrato- } \mathrm{NO}_{3}{ }^{-} \\
(\mathrm{mg} / \mathrm{L})\end{array}$ & 10,0 & 10,0 & 0,70 & 0,71 & 0,70 & 0,73 & 0,72 & 0,714 \\
\hline $\begin{array}{l}\text { Nitrogênio - total } \\
(\mathrm{mg} / \mathrm{L})\end{array}$ & $* *$ & $* *$ & 0,60 & 0,64 & 0,63 & 0,66 & 0,70 & 0,65 \\
\hline $\begin{array}{l}\text { Sulfato- } \mathrm{SO}_{4}{ }^{2-} \\
(\mathrm{mg} / \mathrm{L})\end{array}$ & 250 & 250 & 1,58 & 1,57 & 1,45 & 1,81 & 1,67 & 1,61 \\
\hline $\begin{array}{l}\text { Carbono Org. } \\
(\mathrm{mg} / \mathrm{L})\end{array}$ & * & * & 8,28 & 6,61 & 7,15 & 7,37 & 7,40 & 7,36 \\
\hline $\begin{array}{l}\text { Carbono } \\
\text { Inor.(mg/L) }\end{array}$ & * & * & 3,36 & 3,55 & 3,35 & 3,68 & 3,81 & 3,55 \\
\hline $\begin{array}{l}\text { Carbono total } \\
(\mathrm{mg} / \mathrm{L})\end{array}$ & * & * & 11,64 & 10,17 & 10,50 & 11,05 & 11,21 & 10,91 \\
\hline $\mathrm{OD}\left(\mathrm{mg} / \mathrm{LO}_{2}\right)$ & 6 & 4 & 7,3 & 6,8 & 6,5 & 6,3 & 5,8 & 6,54 \\
\hline
\end{tabular}

$\mathrm{mg} / \mathrm{L} \mathrm{e} 1,99 \mathrm{mg} / \mathrm{L}$ respectivamente, quando comparados com a resolução CONAMA 357/2005, que determina $1,4 \mathrm{mg} / \mathrm{L}$ para os íons fluoreto e $250 \mathrm{mg} / \mathrm{L}$ para os íons cloretos em águas de classe I e II.

A Portaria n⿳0 518/04 do Ministério da Saúde, estabelece o valor máximo permitido para fluoreto de 1,5 mg/L na água potável (BRASIL, 2004). Gerber (2009), relata que para ingerir esta concentração é necessário o consumo de 1,2 a 1,6 litros de água tratada com 1,0 mg/L de fluoreto. Já a presença de cloretos é justificada devido à salinidade da água, embora os valores encontrados tenham sido baixos em todos os pontos analisados. A contaminação com os íons cloretos segundo Gerber (2009), pode indicar contaminação fecal.

A resolução CONAMA 357/2005 determina uma concentração máxima de $0,025 \mathrm{mg} / \mathrm{L}$ de fósforo para águas 
de classe I. Para águas de classe II, essa concentração máxima sobe para $0,075 \mathrm{mg} / \mathrm{L}$. Nas análises realizadas nos pontos RT1, RT2, RT3, RT4, RT5 as concentrações apresentaram 0,147 mg/L; 0,144 mg/L; 0,158 mg/L; 0,155 $\mathrm{mg} / \mathrm{L} ; 0,169 \mathrm{mg} / \mathrm{L}$ respectivamente.

Esta concentração elevada de fósforo pode ser oriunda dos efluentes lançados pelas indústrias, da carga orgânica, da falta de saneamento básico humano, da crescente criação animal na bacia ou ainda ser resultado da aplicação de defensivos agrícolas e fertilizantes, bem como de origem geológica, alterando a concentração natural do nutriente (RELATÓRIO TÉCNICO 4, 2011). CETESB (2009), também relata que o fósforo em águas naturais ocorre principalmente em função das descargas de esgotos sanitários, a matéria orgânica fecal e os detergentes em pó utilizados em grandes quantidades pelas residências.

Nas proximidades da cidade de Lajeado, o rio Taquari é usado para áreas de lazer devido à sua beleza natural, mas há um "grave problema devido à poluição, pois existem muitas ligações clandestinas de esgoto e também muito lixo jogado em suas margens" FERRI (2012, p. 175). Segundo a Fundação Estadual de Proteção Ambiental Henrique Luiz Roessler (FEPAM, 2014), $65 \%$ das águas dos rios da bacia Taqui-Antas estão com alto nível de poluição, cujas possíveis causas são: a influência de elevada concentração de fósforo nos rios; a demanda bioquímica de oxigênio (DBO); a ocorrência de coliformes termotolerantes.

De acordo com CETESB (2009), as águas coletadas em período chuvoso podem afetar a concentração de fósforo, devido a drenagem de áreas agrícolas e urbanas para as águas naturais. A presença de industrias de fertilizantes, pesticidas, conservas alimentícias, matadouros, frigoríficos e laticínios nas margens do corpo d'água também podem contribuir para alterar a concentração do fósforo em quantidades excessivas.

Von Sperling (2005) discute que fósforo em águas naturais apresenta-se principalmente na forma de ortofosfato, polifosfato e fósforo orgânico. O ortofosfato pode ser metabolizado pelos seres vivos sem conversão para formas mais simples, já os polifosfatos, devido a sua complexidade molecular, podem ser mais danosos ao ambiente.

Nas análises realizadas em todas as formas de oxidação do nitrogênio: Nitrogênio - total; Nitrito $\left(\mathrm{NO}_{2}^{-}\right)$; Nitrato $\left(\mathrm{NO}_{3}^{-}\right)$; os valores médios estiveram bem abaixo dos valores estipulados pela resolução CONAMA 357/2005, conforme se apresenta na tabela 1. Para o nitrogênio amoniacal a resolução preconiza valores a depender do $\mathrm{pH}$, para as águas de classe I e II o $\mathrm{pH}</=7,5$ podendo ter o limite de concentração até 3,7 mg/L, e pH igual 7,5 esse limite máximo é de 2,0 $\mathrm{mg} / \mathrm{L}$. Os valores médios encontrados foram de: 0,65 $\mathrm{mg} / \mathrm{L}$ para o nitrogênio total; $0,03 \mathrm{mg} / \mathrm{L}$ para o nitrito e $0,714 \mathrm{mg} / \mathrm{L}$ para o nitrato.

O nitrogênio é um parâmetro frequentemente utili- zado para caracterizar águas de abastecimento público e residuárias brutas e tratadas. É fundamental ao crescimento dos microrganismos que degradam a matéria orgânica e sevem para indicar a poluição por esgoto. Seu excesso contribui para a ocorrência da eutrofização. O nitrogênio na forma de $\mathrm{NO}_{3}$ ' está associado a poluição remota e a doenças como a metahemoglobinemia (síndrome do bebê azul), a poluição recente está associada à presença de nitrogênio na forma de amônia e orgânica. (VON SPERLING, 2005).

$\mathrm{O}$ sulfato $\left(\mathrm{SO}_{4}{ }^{2-}\right)$ é um dos íons encontrados em maior quantidade na natureza. São encontrados na água devido à lixiviação das rochas sedimentares, pela oxidação de sulfetos, pela presença de matéria orgânica, os despejos industriais, bem como pelo uso de coagulantes do tratamento águas (CETESB, 2009). Segundo a resolução CONAMA 357/2005, as concentrações máximas de sulfato para águas de classe I e II é de $250 \mathrm{mg} / \mathrm{L}$. Concentrações acima destes valores não são recomendadas para água de abastecimento público, pois a sua ingestão provoca efeito laxativo (CETESB, 2009).

As concentrações de sulfato estão abaixo dos valores máximos estabelecidos pela resolução CONAMA 357/2005, sendo que nos pontos de RT4 e RT5 os valores são maiores em relação aos demais.

Os parâmetros carbono orgânico, carbono inorgânico e carbono total não são referenciados pela resolução CONAMA 357/2005. De acordo com CETESB (2009), o carbono orgânico total é a concentração de carbono orgânico oxidado a CO2, em um forno a alta temperatura.

A matéria viva e vários efluentes e resíduos são a origem do carbono orgânico em água doce. Raymond e Cole (2003), discutem que a entrada de carbono pode ocorrer através da erosão química de rochas, que são facilitadas pela reação com o dióxido de carbono atmosférico. Esse carbono é útil ao ambiente por ser fonte de energia para bactérias e algas, além de sua importância ambiental para complexar metais. A presença de algas cianofíceas em decomposição pode, em concentrações elevadas, tornar-se tóxica, além de causar problemas estéticos. O carbono orgânico total na água também é um indicador útil do nível de poluição da água.

Nos resultados das análises encontrou-se valores médios de 7,36 mg/L, 3,55 mg/L, 10,91 mg/L para os parâmetros de carbono orgânico, carbono inorgânico e carbono total, respectivamente. Os resultados analíticos nos pontos indicaram um valor maior da concentração de carbono orgânico em relação ao carbono inorgânico, sendo no ponto RT1 as concentrações são 8,28 mg/L e 3,36 mg/L, respectivamente para carbono orgânico e inorgânico. Uma queda no teor de carbono orgânico para o inorgânico em um mesmo ponto de coleta pode estar relacionado à maior quantidade de vegetação e ou compostos orgânicos oriundos da ação antropogênica.

As formas de carbono inorgânico presentes no ambiente aquático são: dióxido de carbono dissolvido 
$\left(\mathrm{CO}_{2}(\mathrm{aq})+\mathrm{H}_{2} \mathrm{CO}_{3}+\mathrm{HCO}_{3}{ }^{-} \mathrm{e} \mathrm{CO}_{3}{ }^{2-}\right)$. Essas três formas se encontram em equilíbrio na água e são importantes por contribuir para a produtividade primária, nas cadeias alimentares e na sucessão biológica. A principal fonte de carbono inorgânico nesses sistemas é o gás carbônico $\left(\mathrm{CO}_{2}\right)$, originado da respiração e decomposição de seres vivos, ou dissolução de sedimentos carbonatados (ESTEVES, 1998).

É raro o equilíbrio químico do carbono na água em sistemas aquáticos naturais. $\mathrm{O} \mathrm{CO}_{2}$ presente na água provêm especialmente da atmosfera, da respiração e da decomposição e pode apresentar-se sob diferentes formas químicas. $\mathrm{O} \mathrm{CO}_{2}$ reage com a água, numa proporção menor que $1 \%$ é hidratado e forma o ácido carbônico: $\mathrm{CO}_{2}+\mathrm{H}_{2} \mathrm{O} \rightarrow \mathrm{H}_{2} \mathrm{CO}_{3}$. Uma parte do ácido carbônico formado se dissocia e forma bicarbonato e íons hidrogênio reduzindo o $\mathrm{pH}: \mathrm{H}_{2} \mathrm{CO}_{3} \rightarrow \mathrm{HCO}_{3}^{-}+$ $\mathrm{H}^{+}$. A terceira reação resulta em outro próton livre: $\mathrm{HCO}_{3}{ }^{-} \rightarrow \mathrm{CO}_{3}{ }^{2-}+\mathrm{H}+($ PIERINI e THOMAZ, 2004).

Dentre os parâmetros nos quais o carbono inorgânico interfere está a alcalinidade, tida como a capacidade de tamponamento no ambiente aquático. Nos resultados apresentados neste trabalho, o pH médio das análises realizadas foi de 7,52, o que pode ser um indicativo da presença de poucas espécies de carbono inorgânico. Variações no $\mathrm{pH}$ podem afetar o equilíbrio químicos de dissolução e dissociação do gás carbônico, podendo alterar as concentrações nas três formas de Carbono inorgânico $\left(\mathrm{CO}_{2}, \mathrm{HCO}_{3}^{-}, \mathrm{CO}_{3}{ }^{2-}\right)$, provocando mudanças no $\mathrm{pH}$ e na alcalinidade da água (ZEEBE e WOLF-GLADROW, 2001).

Segundo Von Sperling (2004) e Fiorucci, Benedetti Filho (2005) a solubilidade do oxigênio varia com a altitude e a temperatura e condições naturais. As boas condições de oxigenação viabilizam a depuração da matéria orgânica, mas, conforme FEPAM (2014), o rio Taquari tem pouca velocidade, poucas corredeiras e o leito é arenoso, reduzindo a capacidade auto depurante.

Os resultados das análises evidenciaram uma concentração média de 6,54 mg/L de oxigênio $\left(\mathrm{O}_{2}\right)$ dissolvido. Observa-se que o resultado das análises variou, reduzindo a concentração do oxigênio dissolvido na medida em que se aproximava do centro das cidades. Isso possibilita deduzir um aumento da atividade antrópica com a disposição de matéria orgânica, exigindo oxidação e consequentemente uma diminuição de sua concentração. No ponto RT5 essa concentração chegou a 5,8 mg/L. Von Sperling (2004) afirma que quando os

Tabela 2 - Resultado das análises microbiológicas

\begin{tabular}{|c|c|}
\hline AMOSTRA & RESULTADOS \\
\hline RT1 & $\begin{array}{l}\text { Presença de muita matéria orgânica dissolvida, provavelmente, } \\
\text { proveniente de fezes, presença de helmintos no estágio de ovo com } \\
\text { um núcleo mais escuro; Espécie: Ascaris lumbricoides. }\end{array}$ \\
\hline RT2 & $\begin{array}{l}\text { Presença de grande quantidade de microalgas e Matéria orgânica } \\
\text { em decomposição. }\end{array}$ \\
\hline RT3 & $\begin{array}{l}\text { Presença intensa de microalgas; Várias euglenas - Euglenophyta; } \\
\text { Vários ovos de Ascaris lumbricoides e Paramecium sp; Presença } \\
\text { também de protozoário no estágio de cisto com oito núcleos; e } \\
\text { Espécies: Giárdia lamblia. }\end{array}$ \\
\hline RT4 & $\begin{array}{l}\text { Matéria orgânica; presença de euglena - Euglenophyta; Vários } \\
\text { ovos de Ascaris lumbricoides. }\end{array}$ \\
\hline RT5 & Matéria Orgânica dissolvida. \\
\hline
\end{tabular}


valores estão bem abaixo da saturação $(9,2 \mathrm{mg} / \mathrm{L})$ são sugestivos da existência de matéria orgânica, podendo causar a morte dos peixes mais exigentes se o oxigênio alcançar a concentração próxima de 4 a $5 \mathrm{mg} / \mathrm{L}$.

Por outro lado FEPAM (2014), apresenta a concentrações de oxigênio dissolvido nos rios das Antas e o Rio Taquari como de boas condições de oxigenação, com predominância da Classe 1. As medias anuais no rio Taquari apresentam valores em torno de 6,0 e 7,0 mg/L.

Comparando os resultados das medidas de $\mathrm{O}_{2}$ dissolvidos com as concentrações de nitrogênio e carbono (tabela 1), as diferenças de valores são pequenas, mas evidenciam um consumo de oxigênio para conversão de $\mathrm{NO}_{2}^{-}$a $\mathrm{NO}_{3}^{-}$. As taxas de carbono orgânico também aumentaram na medida em que os pontos se aproximam do centro da cidade de Lajeado-RS (RT1 a RT5).

\subsection{Resultados das análises Microbiológicas}

A presença de microrganismos identificados nas amostras analisadas ao microscópio óptico indicam a intensa atividade microbiana, conforme observa-se na tabela 2.

O meio favorece a transmissão de parasitoses, uma vez que grande parte de protozoários parasitas necessitam de lugares úmidos, quentes e sombreados para atravessarem o processo evolutivo de três ou quatro semanas. A água contaminada é um veículo que favorece a proliferação deste microrganismos patogênico, podendo comprometer a saúde humana por meio de sua ingestão (STORER, 1989).

A presença de Ascaris lumbricoides, cuja ingestão de ovos férteis pode levar os indivíduos a desenvolver Ascaridíase, doença parasitária causada por este agente infeccioso, chamada popularmente de lombriga. Leciona Campos et al., (2002 p. 70) que: "a prevalência elevada de A. lumbricoides está associada a precárias condições sanitárias, constituindo importante indicador do estado de saúde de uma população".

Nas análises realizadas por meio desta investigação constatou-se a presença excessiva de ovos de Ascaris lumbricóides nos locais de coleta RT1, RT3, RT4. Em observação in loco nestes pontos detectou-se alterações nas características socioambientais. Isto vem ao encontro do que foi detalhado nos estudos de Campos et al., (2002): a renda familiar, o nível de escolaridade, as condições peridomiciliares próximos aos corpos d'água, corrobora para a influência do peridomicílio na ascaríase.

A presença desses ovos indica a possível falta de saneamento básico adequado. Desta forma é possível aferir que os dejetos humanos podem estar sendo despejados diretamente nas águas, ou nas proximidades das vazantes do rio Taquari. Segundo a revista saúde e medicina (2013), a contaminação por A. lumbricoides possibilita complicações para saúde humana e até mesmo o risco de morte.
Para Campos et al., (2002 p. 70), “a identificação de áreas de risco de A. lumbricoides é fundamental para o controle eficiente desse patógeno". Neves (1998), diz que ações de saneamento básico que busquem estratégias de controle deste patógeno são imprescindíveis. Nessa perspectiva vislumbra-se a importância de uma "identificação acurada de áreas de risco (as quais asseguram) uma maior eficiência em ações de controle do parasito, otimizando recursos e minimizando gastos" (CAMPOS et al., 2002 p. 74).

\section{Conclusões}

$\mathrm{O}$ rio Taquari apresenta boa qualidade de suas águas, e na maior parte dos resultados, os parâmetros analisados estão em conformidade com os padrões estabelecidos pela resolução CONAMA 357/2005, exceto para o parâmetro Fósforo. Nos parâmetros químicos e físicos analisados percebeu-se alterações na concentrações nas análises à medida que os pontos se aproximam do centro da cidade de Lajeado-RS. Identificou-se um aumento da concentração de Fósforo de forma gradativa dos pontos RT1 à RT5, além da redução na concentração do oxigênio dissolvido e aumento na concentração de nitrito, nitrato, carbono orgânico e inorgânico e uma redução no valor do pH nos pontos RT4 e RT5. Estas alterações são um indicativo de poluição por esgoto doméstico ou industrial.

As análises microbiológicas, confirmam a possibilidade de contaminação por esgoto doméstico, ao ser encontrado grandes quantidades de ovos de Ascaris lumbricoides.

O acesso a informação consiste em um fator de elevada relevância na prevenção e transmissão de doenças, deste modo, a disposição dos dados elencados por meio dessa investigação visa contribuir com a disseminação de conhecimentos acerca da qualidade das águas do Rio Taquari e consequentemente disponibilizar informações que auxiliem o poder público e a sociedade na tomada de decisões locais a fim de buscarem a melhoria nas condições de saneamento básico dos municípios pesquisados.

\section{Referências bibliográficas}

ALPHA. Standard methods for the examination of water and wastewater. 25. ed American Publish Health Association, 1998.

BRASIL. Ministério do Meio Ambiente, Conselho Nacional do Meio Ambiente - CONAMA.

Resolução no 420 de 28 de Dezembro de 2009. Brasília: 2009. Disponível em: <http://www.mma. gov.br/port/conama/res/res09/res42009.pdf. >. Acesso em: 16 de jan. 2014. 
BRASIL. Ministério do Meio Ambiente, Conselho Nacional do Meio Ambiente - CONAMA. Resolução nº 357 de 17 de Março de 2005. Brasília: 2005. Disponível em: <http://www.mma.gov.br/ port/conama/res/res05/res35705.pdf. >Acesso em: 16 de jan. 2014.

BRASIL. Ministério da saúde.Resolução de 518 de 25 de março de 2004. Brasília: 2004. Disponível em: <http://dtr2001.saude.gov.br/sas/PORTARIAS/ Port2004/GM/GM-518.htm.> Acesso em: 05 março de 2014.

CAMPOS, M. R.; VALENCIA, L. I. O.; FORTES, B. P. M. D; BRAGA, R. C. C.; MEDRONHO, R. A. Distribuição espacial da infecção por Ascaris lumbricoides. São Paulo: Revista Saúde Pública, v. 36 n. 1 p. 69-74, 2002. Disponível em:<http://www. scielo.org/php/index.php. >Acesso em: 5 Mar. 2014.

CAOVILLA, F. A.; SAMPAIO, S. C.; PEREIRA, J. O.; BOAS, M. A. V.; GOMES, B. M.; FIGUEIRÊDO, A. C. Lixiviação de nutrientes provenientes de águas residuárias em colunas de solo cultivado com soja. Revista Brasileira de Engenharia Agrícola e Ambiental, v.9, p.283-287, 2005.

CETESB - Companhia Ambiental do Estado de São Paulo - Significado ambiental e sanitário das variáveis de qualidade das águas e dos sedimentos e metodologias analíticas e de amostragem. IN: Qualidade das águas interiores no estado de São Paulo. Apêndice A - Governo do Estado de São Paulo. Secretaria do Meio Ambiente. 2009.

CUNHA, D. G. F.; CALIJURI, M. C. LAMPARELLI, M. C. MENEGON Jr. N. Resolução CONAMA 357/2005: análise espacial e temporal de não conformidades em rios e reservatórios do estado de São Paulo de acordo com seus enquadramentos (2005-2009). Revista de Engenharia Sanitária Ambiental, v.18 n.2, abr/jun, 2013.

ESTEVES, F.A. Sedimentos límnicos. In: Esteves, F.A. Fundamentos de Limnologia. 2 ed. Rio de Janeiro: Interciência. p. 300-315. 1998.

FEPAM - Fundação Estadual de Proteção Ambiental Henrique Luiz Roessler. RIO GRANDE DO SUL. Qualidade ambiental: qualidade das águas da Bacia Hidrográfica do Rio das Antas e do Rio Taquari. Disponível em:<http://www.fepam.rs.gov.br/ qualidade/taquariantas.asp $>$. Acesso em: 22 jun. 2014.

FERRI, G. A., TOGNI, A. C. A história da bacia hidrográfica Taquari-Antas. Ed. da Univates.
Lajeado, 2012.

FIORUCCI A. R.; BENEDETTI FILHO, E., Oxigênio dissolvido em sistemas aquáticos. Química Nova Na Escola. n 22, nov. 2005.

GARCIA, C. A. B.; ALVES, J. P. H. Qualidade da água. Relatório de Pesquisa -LQA/UFS. São Cristóvão, 2006. In: Diagnóstico e avaliação da sub-bacia hidrográfica do rio Poxim. Relatório de Pesquisa. UFS/FAPESE. São Cristóvão, 2006.

GERBER, A. C.; RICORDI, V. G.; MILANI, I. C. B.; NEBEL, Á. L. C.; TAVARES, V. E.; SUZUKI, L. E. A. S.; COLLARES, G. L. Avaliação da qualidade da água de propriedades rurais com sistema de produção de leite. In: XVIII Congresso de Iniciação Científica e XI Encontro de Pós-Graduação. 2009, Pelotas. XVIII CIC e XI ENPOS Evoluir sem extinguir: por uma ciência do devir, 2009. disponível em: <http://wp.ufpel.edu.br/rhima/ files/2010/09/CA_00368.pdf.> acesso em 03/03/2014.

\section{KEDIMERICH, P. D. C., CANTO, L. S. DESCOVI} FILHO, L. L. V., UCKER, F. E., TEIXEIRA, L. C., TEIXEIRA, M. C.. Variação espacial da qualidade da água subterrânea em área ocupada por cemitério tipo parque jardim. Engenharia Ambiental. Espírito Santo do Pinhal, v. 9, n. 3, p. 264-279, jul/set. 2012.

LIMA, W. S., GARCIA, C. A. B., Qualidade da Água em Ribeirópolis-SE: O Açude do Cajueiro e a Barragem do João Ferreira. Scientia plena, v. 4, nº 12. 2008.

MEZOMO, À. M. (Org.); DANIEL, J. E. S; BALDISSERA, C. M.; SCHENKEL, R. S.; DOMENIGHI, J. O. M.; COLLE, C. A.; Irrigação é a solução: manual técnico de apoio. Porto Alegre: EMATER/RS-ASCAR, 2009.

MONTEIRO, V. P.; PINHEIRO, J. C. Critério para implantação de tecnologias de suprimentos de água potável em municípios cearenses afetados pelo alto teor de sal. Revista de Economia e Sociologia Rural, v.42, p.365-387, 2004.

NEVES P. D. Parasitologia humana. 7a. ed. Rio de Janeiro: Editora Atheneu; 1998.

PIERINI, S. A., THOMAZ, S. M. Adaptações de plantas submersas à absorção do carbono inorgânico. Artigo de revisão Acta bot. bras. V. 18 n. 03 pag. 629-641. 2004.

PINHEIRO, A.; DESCHAMPS, F. C. Transporte de 
ortofosfato e de nitrato na Microbacia do Ribeirão Fortuna, SC. Revista Brasileira de Engenharia Agrícola e Ambiental, v.12, p.318- 325, 2008.

PINHEIRO, A., PINHEIRO, V., SCHNEIDERS D., OLIVEIRA, D. A., ALBANO R. M. R. Concentrações e cargas de nitrato e fosfato na Bacia do Ribeirão Concórdia, Lontras, SC. Revista Bras. Eng. Agrícola e Ambiental, v.17, n.1, p.86-93, 2013.

PIOVESAN, R. P.; FAVARETTO, N.; PAULETTI, V.; MOTTA, A. C. V.; REISSMANN, C. B. Perdas de nutrientes via subsuperfície em colunas de solo sob fertilização mineral e orgânica. Revista Brasileira de Ciência do Solo, v.33, p.757-766, 2009.

RAYMOND, P. A.; COLE, J. J. Increase in the Export of Alkalinity from North America's Largest River. Science, Vol. 301 no. 5629 pp. 88-91, Julho, 2003. Disponível em: <https://www.sciencemag.org/ content/301/5629/88.> Acesso em 03 de fevereiro de 2014.

RELATÓRIO TÉCNICO 2 - Comitê de Gerenciamento da Bacia Hidrográfica Taquari-Antas. fase A: diagnóstico e prognóstico: etapa A. 3: consolidação do diagnóstico. RT2. 2011. Disponível em: <http:// http://www.taquariantas.com.br/site/home/pagina/ id/35>. Acesso em: 16 jan. 2014.

RELATÓRIO TÉCNICO 4 - Comitê de Gerenciamento da Bacia Hidrográfica Taquari-Antas. fase A: diagnóstico e prognóstico: etapa A. 3: consolidação do diagnóstico. Relatório. RT4 2011b, TOMO, II, P5, 121 Disponível em: <http:// http://www. taquariantas.com.br/site/home/pagina/id/35>. Acesso em: 16 jan. 2014.

REVISTA SAÚDE E MEDICINA. Informações sobre saúde e doenças: São Paulo/SP. Disponível em:< http://www.saudemedicina.com/> Acesso em; 20 fev. 2014.

SILVA, D. F., GALVÍNCIO, J. D., ALMEIDA, H. R. R. C. Variabilidade da qualidade de água na bacia hidrográfica do Rio São Francisco e atividades antrópicas relacionadas. Qualit@s Revista Eletrônica Vol.9. № 3, 2010.

SOARES, D. C. Aspectos Limnológicos do Córrego São Pedro Juiz de Fora - Minas Gerais. 2007.

STORER T. I, USINGER R. L. Zoologia geral. São Paulo: Editora Nacional; 1989.

TOLEDO, L. G.; NICOLELLA, G. Índice de qualidade de água em microbacia sob uso agrícola e urbano.
Scientia Agricola, v.59, p.181-186, 2002.

TEODORO, V. L. I.; TEIXEIRA, D.; COSTA, D. J. L.; FULLER, B. B. O conceito de bacia hidrográfica e a importância da caracterização morfométrica para o entendimento da dinâmica ambiental local. Revista Uniara, n.20, p.137-157, 2007.

VON SPERLING, M. Princípios do Tratamento Biológico de Águas Residuárias - Introdução à qualidade das águas e ao tratamento de esgotos, $3^{\text {a }}$ edição. v.01. Minas Gerais: ABES, 2005.

ZEEBE, R. E.; WOLF-GLADROW, D. CO2 in Seawater: Equilibrium, Kinetics, Isotopes. Elsevier Oceanography Series, 346 p. 2001.

ONU - ORGANIZAÇÃO DAS NAÇÕES UNIDAS. Declaração Universal dos Direitos da Água, 1992. Disponível em: <http://www.cetesb.sp.gov.br/agua/ aguas-superficiais/40-declaracao-universal-dosdireitos--da-agua $>$. Acesso em: 02 de fevereiro de 2014. 